\title{
BMJ Open Multiple challenges for people after transitioning to secondary progressive multiple sclerosis: a qualitative study
}

\author{
Angeliki Bogosian, ${ }^{1}$ Myfanwy Morgan, ${ }^{2}$ Rona Moss-Morris ${ }^{3}$
}

To cite: Bogosian A, Morgan M, Moss-Morris R. Multiple challenges for people after transitioning to secondary progressive multiple sclerosis: a qualitative study. BMJ Open 2019;9:e026421. doi:10.1136/ bmjopen-2018-026421

- Prepublication history for this paper is available online. To view these files, please visit the journal online (http://dx.doi. org/10.1136/bmjopen-2018026421).

Received 3 September 2018 Revised 4 January 2019 Accepted 11 January 2019

\section{Check for updates}

\section{(c) Author(s) (or their} employer(s)) 2019. Re-use permitted under CC BY-NC. No commercial re-use. See rights and permissions. Published by BMJ.

${ }^{1}$ School of Health Sciences, City University of London, London, UK

${ }^{2}$ Institute of Pharmaceutical Science, King's College London, London, UK

${ }^{3}$ Institute of Psychiatry, King's College London, London, UK

Correspondence to

Dr Angeliki Bogosian;

angeliki.bogosian.1@city.ac.uk

\section{ABSTRACT}

Objectives Transitioning to secondary progressive multiple sclerosis (SPMS) is demanding for both patients and healthcare professionals. The particular challenges and the ways patients cope are poorly understood. The present study examines what challenges people face when diagnosed with SPMS by exploring experiences of people who have transitioned recently (up to 5 years).

Design Semistructured qualitative interviews at two time points a year apart. Interviews were analysed using inductive thematic analysis.

Setting UK.

Participants We interviewed 21 people at baseline and 17 participated in the follow-up interviews.

Results The majority of participants reported expecting to transition to SPMS, and the diagnosis did not make much difference to them. Participants described increasing emotional and physical challenges after transitioning to SPMS and between the first and second interviews. Planning, using distractions and maintaining social roles helped participants cope with the increased challenges. The same coping strategies were used between the two interviews. Participants felt there was not much left to do regarding the management of their symptoms. A key theme was the sense of abandonment from healthcare services after transitioning to SPMS.

Conclusions After transitioning to SPMS, people are faced with multiple challenges. Participants described a lack of directions for symptoms management and lack of support from the healthcare system. An integrated multidisciplinary healthcare approach is crucial at the progressive stage of the disease to alleviate feelings of helplessness and promote symptom management.

\section{INTRODUCTION}

Multiple sclerosis (MS) affects more than 2.5 million people worldwide, including 127000 in the UK. ${ }^{1}$ MS is a condition that presents unique challenges for the individuals, as it usually starts with minimal physical and cognitive dysfunction that progresses over time. There are three types of MS. The most common type is relapsing-remitting (RRMS)-, 85\%-90\% of people with MS are diagnosed with this type), which is characterised by unpredictable attacks (relapses) of new or increasing neurological symptoms that

\section{Strength and limitations of this study}

The present study is the first to use a longitudinal qualitative design to capture peoples' experience after transitioning to secondary progressive multiple sclerosis.

- The focus on people recently transitioned helped to narrow down peoples' experiences early on in diagnosis.

- We cannot determine whether the challenges described in this study are linked to having received an official diagnosis or to the challenges faced by increased disability, as we did not interview people just before being diagnosed and straight after.

are followed by periods of partial or complete recovery (remissions). ${ }^{2}$ The secondary progressive (SPMS) course develops in approximately $82 \%$ of those with RRMS by 20 years of onset. ${ }^{3}$ Finally, a minority of people $(10 \%)$ will be diagnosed with the primary progressive (PP) course that involves a steady disability increase without attacks. ${ }^{4}$

The transition to SPMS is an expected part of the disease trajectory. Epidemiological studies indicate nearly $10 \%$ of people with RRMS reach the SPMS stage after 5 years, which increases to $25 \%$ at 10 years and $75 \%$ at 30 years. ${ }^{5}$ A mean of $2.9 \pm 0.8$ years is a typical length of time when people are faced with the uncertainty of whether they have transitioned to SPMS. ${ }^{6}$ The delay in the diagnosis is thought to be due to the subtle nature of early progression and clinicians' reluctance to label a patient as having SPMS, given the absence of evidence-based treatment for SPMS and patients' anxieties regarding its prognosis. ${ }^{6}$ People with SPMS are older, are less likely to be employed and a lower proportion is female when compared with people with RRMS. ${ }^{7}$ When people transition to SPMS, they are likely to experience more severe neurological symptoms, more frequent hospitalisation, ${ }^{8}$ have more frequent and pronounced cognitive deficits $^{9}{ }^{10}$ and higher levels of fatigue $\mathrm{e}^{11}$ compared with people with RRMS. The onset of 
SPMS has also been associated with fear, low mood, ${ }^{12}$ greater distress ${ }^{1314}$ lower quality of life ${ }^{15}$ and higher levels of depression and anxiety ${ }^{16}$ than in both RR and PP types of MS. Only four qualitative studies have been conducted to examine the experiences of people with SPMS. In two of these studies, women with SPMS recognised the impact of the loss of meaningful activities on the sense of self. ${ }^{17} 18$ A qualitative study on patients' experiences while transitioning to SPMS showed that some people learnt they had SPMS without any advanced knowledge or understanding of what SPMS meant for them, which sometimes caused confusion and upset. ${ }^{19}$ In the fourth study, MS health professionals highlighted the value of adequate information and support around the transition period, while patients talked about the reclassification with SPMS as a turning point. ${ }^{20}$

We know little about peoples' experiences after transitioning to SPMS, and psychological and behavioural interventions aimed at people with SPMS are scarce. Furthermore, a recent meta-analysis on the effectiveness of interventions for treating depression in MS identified 13 papers, with 8 of these excluding people with progressive MS from participating. ${ }^{21}$ When people with SPMS are included in psychological interventions, they also seem to gain fewer benefits compared with people with RRMS. ${ }^{22}$ The psychological challenges that people with SPMS face may, therefore, differ to the ones that people with RRMS face.

In this study, we explored psychological and physiological challenges people experience after transitioning to SPMS and the strategies they use to manage those challenges over time. Knowing the challenges that patients face at this stage of their MS trajectory makes it easier to identify information needs and tailor support interventions.

Furthermore, it is not well understood how transitioning to SPMS contributes to psychological challenges and adjustment attempts. The present study is the first to use a longitudinal qualitative design to capture peoples' experience shortly (within 5 years) after transitioning, so recollection of transition is recent and also there is time for people to have developed new coping strategies. The follow-up interviews allowed respondents to reflect on the changes (or lack of them) since the first interview. The focus on people recently transitioned helped to narrow down peoples' experiences early on in diagnosis.

\section{METHODS}

\section{Patients and public involvement}

This research was part of a larger research project, and two individuals with SPMS were part of our user involvement committee, and they have helped with different aspects of the project from the initial conceptualisation of the study, feedback on the grant application and feedback of the topic guide. They were also asked to assess the burden of participation in the study. The two people with SPMS gave us feedback on an initial version of our themes. They inquired about whether the experiences differ based on the age of diagnosis or whether the people who described more psychological challenges had also reported cognitive difficulties. Following this, we checked the emerging themes to identify any patterns or differences in themes of people with different demographic characteristics. The two people with SPMS also suggested exploring further the experience of diagnosis and the importance of receiving the diagnosis of SPMS from a healthcare professional. Finally, they commented on the clarity of description and presentation of the results, for example, they made some suggestions about how themes linked together and asked for a few additional quotes at places to better illustrate themes. Participants of the study were sent the final results of the study but were not asked to provide feedback.

\section{Participants}

This research is part of an MS Society UK-funded junior research fellowship awarded to the first author with a view to increasing understanding of psychological challenges

\begin{tabular}{|c|c|}
\hline Participants' characteristics (T1) & Number (\%) \\
\hline Age (mean, SD) & $57.33(9.13)$ \\
\hline Gender: female & $16(72.7)$ \\
\hline \multicolumn{2}{|l|}{ Marital status } \\
\hline Married/cohabiting & $15(71.4)$ \\
\hline Single & $3(14.3)$ \\
\hline Divorced/separated & $3(14.3)$ \\
\hline \multicolumn{2}{|l|}{ Time since initial diagnosis } \\
\hline $0-5$ years & $5(23.8)$ \\
\hline $6-10$ years & $3(14.3)$ \\
\hline $11-15$ years & $3(14.3)$ \\
\hline 16-20years & $2(9.5)$ \\
\hline $21+$ years & $8(38.1)$ \\
\hline \multicolumn{2}{|l|}{ Time since SPMS diagnosis } \\
\hline 1 year & $4(18.2)$ \\
\hline 2 years & $3(13.6)$ \\
\hline 3 years & $3(13.6)$ \\
\hline 4 years & $4(18.2)$ \\
\hline 5 years & $7(31.8)$ \\
\hline \multicolumn{2}{|l|}{ Walking ability (with aid) } \\
\hline $\begin{array}{l}0-5 \text { m (Expanded Disability Status } \\
\text { Scale (EDSS) 7-8) }\end{array}$ & $9(42.8)$ \\
\hline $\begin{array}{l}20 \text { m (Expanded Disability Status Scale } \\
\text { (EDSS) 6.5) }\end{array}$ & $3(14.3)$ \\
\hline $\begin{array}{l}100 \text { m (Expanded Disability Status } \\
\text { Scale (EDSS) 6) }\end{array}$ & $3(14.3)$ \\
\hline $\begin{array}{l}200 \text { m (Expanded Disability Status } \\
\text { Scale (EDSS) 5) }\end{array}$ & $4(18.2)$ \\
\hline $\begin{array}{l}500 m \text { (Expanded Disability Status } \\
\text { Scale (EDSS) } \leq 4 \text { ) }\end{array}$ & $1(4.8)$ \\
\hline Unknown & $1(4.8)$ \\
\hline
\end{tabular}

SPMS, secondary progressive multiple sclerosis. EDSS, expanded disability status scale 
and adjustment of people with progressive MS. We recruited participants through online adverts on the MS Society UK website, adverts after speaking engagements at MS Society events and through study's information sheets provided by research nurses at MS hospital clinics (Northamptonshire Healthcare NHS Foundation Trust and Cumbria Partnership NHS Foundation Trust). At that stage through the participants' information sheet, potential participants learnt the aims of the research project and what the researchers were planning to use the information for, that is, develop a psychological intervention tailored to the needs of people with progressive MS. Participants who self-reported that they had received a diagnosis of PPMS and SPMS from their neurologist or MS nurse were recruited, but here we focused on the interviews of people with SPMS. Eighty-seven people with PPMS and SPMS expressed interest in participating in the study. Fifteen (17\%) did not meet the inclusion criterion of diagnosis within 5years of progressive MS. The remaining 72 completed a short screening questionnaire that included demographic questions, as well as questions about MS duration, symptoms and walking ability. We chose to interview people using maximum variation, ${ }^{23}$ that is, sampling to represent different demographic characteristics. No one refused participation after they have been invited to the interview. Participants were recruited from a wide range of locations in the UK, including more rural (small towns) and urban areas. Therefore, there was also a variability on the services they were able to access. Interviewing ceased once data saturation was reached, defined as the point at which no new information or themes are observed in the data. ${ }^{24} \mathrm{We}$ interviewed 21 participants who were diagnosed with SPMS and had given informed consent to take part in the study.

As shown in table 1, participants were between 40 years and 77 years of age (mean: 57.38 years) at the time of the interview. More than half of the sample was unemployed or retired due to MS $(\mathrm{n}=14,66.66 \%)$ and lived with their partners $(\mathrm{n}=15,71.43 \%)$. Half of the participants interviewed $(\mathrm{n}=12,57.1 \%)$ were able to walk for $20 \mathrm{~m}$ or less, which is reflective of the demographics of people with SPMS. Most people with MS accumulate no more than moderate disability (fully ambulatory) during RR phase, ${ }^{25}$ and the onset of the SP phase represents the key determinant of severe disability accumulation. ${ }^{25-27}$ Seventeen participants were interviewed for the second time and four participants $(19 \%)$ did not respond to the email invitations for a second interview, and no reason was provided.

\section{Interviews}

Researchers had not established a relationship with the participants prior to study commencement, with the exception of one participant, who had taken part in a previous study. Participants were given the option of face-to-face or telephone interviews. In the first round, all participants opted for telephone interviews, and the interviews lasted between $26 \mathrm{~min}$ and $160 \mathrm{~min}$ (mean $=79 \mathrm{~min}$ ). Interviews were conducted by the first author ( $\mathrm{AB}$, female). $\mathrm{AB}$ has conducted her MSc, PhD and postdoctoral studies in the area of MS and through her contact with people with MS and her knowledge from the literature has concluded that people with progressive MS are under-represented in the research literature and they feel left out when it comes to treatments and healthcare services. This sparked the interest in the research topic. The initial interviews were conducted between April 2014 and April 2015. The second set of interviews tended to be slightly shorter as they focused on changes between interviews and lasted between $36 \mathrm{~min}$ and 103 min (mean=66.12). With one exception, participants in the second round also opted for telephone interviews. There was no one else present during the interview besides the participant and the researcher $(\mathrm{AB})$. The second round of interviews was conducted between July 2015 and April 2016. There was some variation in the intervals between the first and second interviews, due to staff changing institute and participants' availability. One interview was conducted 13 months after the first interview, seven interviews were conducted 14 months after the first interview, eight interviews were conducted 15 months after the first interview and one interview was conducted 18 months after the first interview. Table 2 shows the topic guide used for the two interviews. Examples people gave in their first interviews were

Table 2 Topic guide

Questions Prompts

Can you start by telling me all about what you thought and felt when you were first diagnosed with MS?

Main issues, explore concerns, feelings (physical, psychological and family issues), what did he or she do about each problem that was identified?

Can you tell me about the time you found out you have moved to secondary progressive type of MS?

Explore how did they find out, period before receiving the diagnosis, thoughts and feelings after receiving the secondary diagnosis.

Can you tell me about what you think and feel about Examples of issues identified? having MS now?

Can you tell me about all the things you found (un) helpful when dealing with challenges of MS?

Feelings and thoughts on support interventions they were offered or sought/how did they apply the advice given (if given), support they would like to see in the future.

Are there any other relevant issues we have not covered that you would like to mention?

MS, multiple sclerosis. 
AB writes summaries after each interview

AB, MM, RMM grouping, comparing and discussion summaries of people with the same demographics

$\mathrm{AB}$ initial coding of interviews using NVivo 10

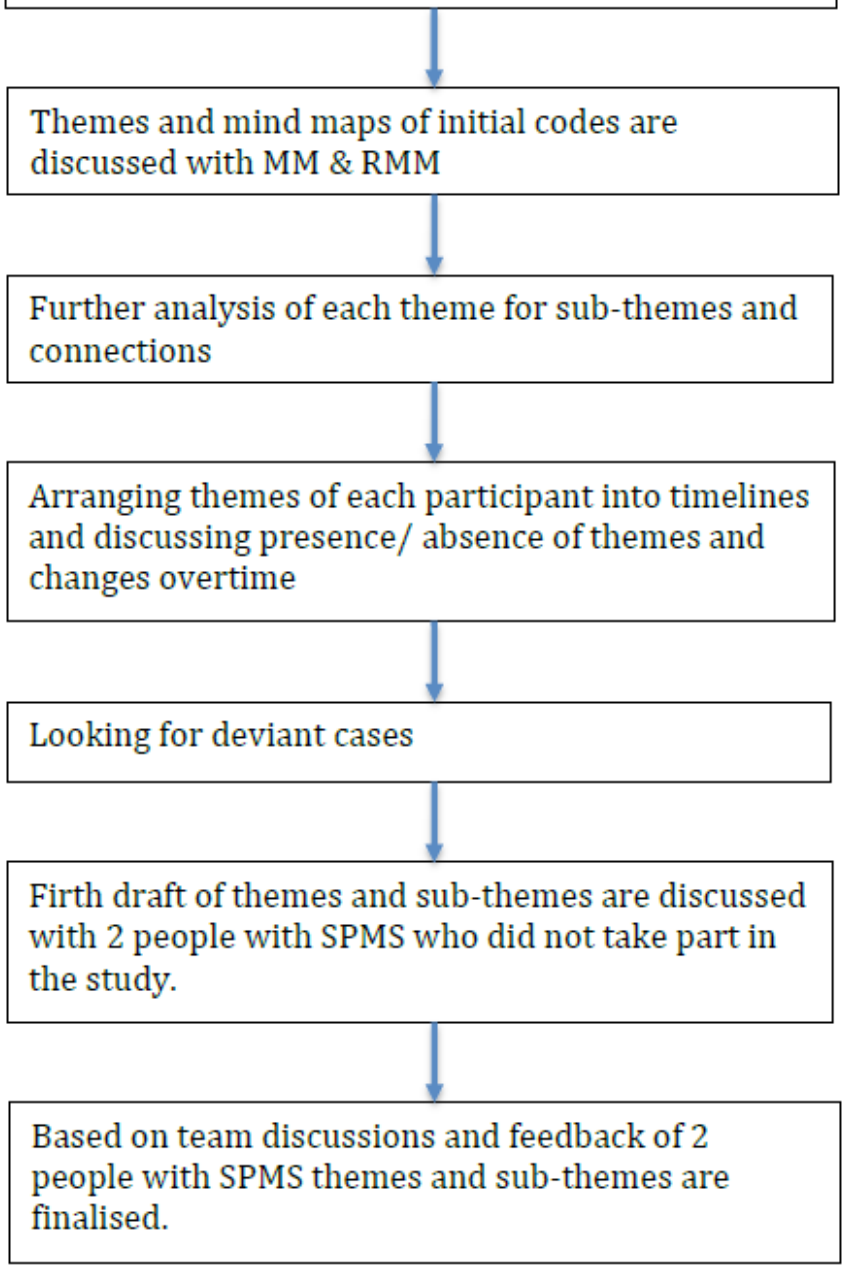

Figure 1 Data analysis flow. SPMS, secondary progressive multiple sclerosis.

also used as prompts to assess changes in emotions, thoughts or symptom management. All interviews were audiotaped with consent and transcribed verbatim. Transcripts were not sent back to participants to comment.

\section{Data analysis}

We used inductive thematic analysis. ${ }^{28}$ An inductive approach means the themes identified emerge from the data themselves. ${ }^{29}$ Therefore, the inductive analysis is the process of coding the data without trying to fit it into a pre-existing coding frame or the researcher's analytic preconceptions. This form of thematic analysis is, therefore, data driven. ${ }^{28}$
Coding was undertaken by the first author $(\mathrm{AB})$ under the supervision of the second author (MM) with discussions of emerging themes with the third author (RM-M). AB has extensive experience analysing qualitative methodologies. She completed qualitative methodologies training as part of the MSc in Health Psychology course (Southampton University) and attended a 2-day workshop on longitudinal qualitative research organised by the Methodological Innovation Network and delivered at Southampton University (November 2012). At the time of this study, the researcher had completed and published three qualitative studies as the lead researcher (conducting of interviews, analysis and write-up), supervised two MSc students and two PhD students on their qualitative methodologies and was teaching a series of qualitative methodologies lectures for MSc and doctoral students. A variety of techniques were employed to increase familiarisation with the data. Audiotapes of each interview were listened repeatedly, and transcripts were read and reread. We used NVivo V.10 for coding.

The analysis of the transcripts was conducted in parallel with data collection and refinement of the themes continued after the end of the data collection, during writing up. First, each coding unit in the first transcript was given a code name, using vocabulary as close as possible to that used by participants themselves. ${ }^{30}$ Initial codes were then applied systematically to the entire dataset, and new codes were developed and refined as appropriate. We also grouped participants' interviews that shared similar demographic characteristics and explored patterns or commonalities. We examined whether themes differed across subgroups (eg, method of recruitment, gender and family circumstances). Figure 1 shows the steps followed during the analysis. The analysis was an iterative process and at times we had to go back and forth between steps. The coding tree in table 3 shows how we moved from codes to refined categories. In order to document the analysis process, a detailed paper trail was kept with the notes taken after the interviews, the development of the codes and relationship between the raw data and the refined categories and codes. The quotes presented in the result section were chosen for typicality in illustrating the themes. Pseudonyms are used for the quotes.

\section{RESULTS}

There are two overarching themes: (1) transitioning to SPMS and challenges and (2) adaptive strategies over time. The first theme illustrated challenges involved in the transition and the second theme related to how participants responded to those challenges. Table 4 provides examples of SPMS transition and challenges over time, and table 5 provides examples of self-management and changes over time. 
Table 3 Coding tree of time 1 and time 2 interviews

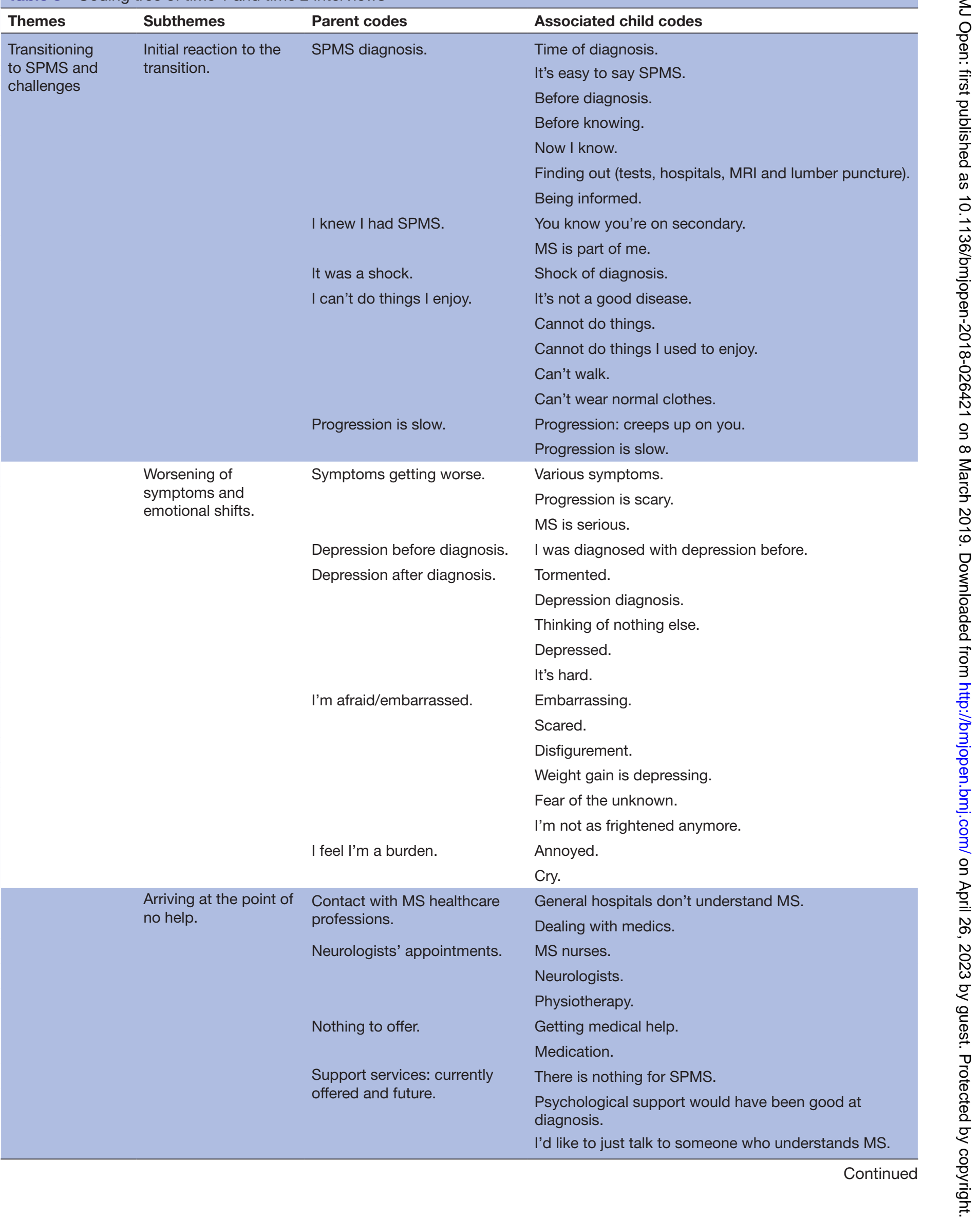


Table 3 Continued

\begin{tabular}{lll}
\hline Themes & Subthemes & Parent codes \\
\hline $\begin{array}{l}\text { Adaptive tasks } \\
\text { and changes } \\
\text { overtime }\end{array}$ & $\begin{array}{l}\text { Planning activities or } \\
\text { scaling down activities. }\end{array}$ & Holidays. \\
& & Planning in advance. \\
& \\
& \\
& & \\
& If you can't do it, do it \\
& differently.
\end{tabular}

Can't do much.

\section{Associated child codes}

Planning holidays.

Cannot plan in advance.

Need to plan meticulously.

Use of diaries/reminders.

Partner showed me a wheelchair is good.

Small things but meaningful.

It's silly to rebel.

Bad days: I do nothing but rest.

Can't exercise.

Life is dull.

Knowing my limits.

\section{Sleeping.}

Daytime TV.

Video games.

Help from partner/family. Partner helps emotionally.

Being outdoors.

Couldn't cope without my partner.

Harder if you're on your own.

Partner looks after me.

Partner control.

Partner gets angry.

Not thinking/talking about the future.

Reading about MS.

I don't like to talk about it.

A frame of mind.

Men cope better.

Young people cope better.

Disrespectful people.

and being of use.

Accessibility problems.

Accessibility issues.

MS group meetings.

Exchanging info.

Comparing with other people.

Comparing with other patients.

Partner organised support group.

Family visits. Grandchildren don't understand.

We're trying to be normal.

We do things for the family.

Family life.

Friendships.

Revealing MS.

I don't look ill.

I have very good friends.

Voluntary work.
Helping others with MS.

I wish I could help.

MS, multiple sclerosis; SPMS, secondary progressive multiple sclerosis.

\section{Transitioning to SPMS and challenges}

Initial reaction to the transition

For the majority of the participants, the transition to SPMS was expected rather than shocking. For some, transitioning did not make much difference because at that point they had already lost essential relationships and activities they valued. For others, transitioning to SPMS did not make much difference because the 
Table 4 Examples of secondary progressive multiple sclerosis (SPMS) transition and challenges over time

\begin{tabular}{|c|c|c|c|}
\hline Interview & P15 & P19 & P12 \\
\hline $\begin{array}{l}\text { Pretransitioning } \\
\text { context }\end{array}$ & $\begin{array}{l}\text { Participant transitioned to SPMS } \\
14 \text { years after initial diagnosis. Before } \\
\text { the MS diagnosis, she was diagnosed } \\
\text { with depression. She needed support } \\
\text { after the diagnosis, but none was } \\
\text { offered. }\end{array}$ & $\begin{array}{l}\text { Participant transitioned to } \\
\text { SPMS } 7 \text { years after initial } \\
\text { diagnosis. Unable to work due } \\
\text { to MS, and he faced financial } \\
\text { difficulties after the diagnosis } \\
\text { of MS. }\end{array}$ & $\begin{array}{l}\text { Participant transitioned to SPMS } \\
21 \text { years after initial diagnosis. } \\
\text { Before the MS diagnosis, she had } \\
\text { a lot of close friends and family } \\
\text { members that she saw regularly. }\end{array}$ \\
\hline Second interview & $\begin{array}{l}\text { Her pain and fatigue were more } \\
\text { severe compared with her first } \\
\text { interview but mobility remained } \\
\text { the same. She was diagnosed with } \\
\text { another autoimmune condition and } \\
\text { with depression. She felt low and } \\
\text { isolated. She was worried about her } \\
\text { other condition and was disappointed } \\
\text { with the lack of support from health } \\
\text { professionals on how to manage her } \\
\text { conditions. }\end{array}$ & $\begin{array}{l}\text { His fatigue and pain were more } \\
\text { severe compared with his first } \\
\text { interview, and he lost bladder } \\
\text { control. Depression was still } \\
\text { present. Feeling isolated and } \\
\text { completely depleted of energy. } \\
\text { He did not think there was } \\
\text { anyway to manage fatigue or } \\
\text { pain or that anyone could help } \\
\text { him. }\end{array}$ & $\begin{array}{l}\text { Her fatigue and pain were worse } \\
\text { compared with her first interview, } \\
\text { and she was not able to exercise } \\
\text { anymore. She was diagnosed with } \\
\text { another long-term condition. Her } \\
\text { healthcare team always had good } \\
\text { suggestions on how to manage her } \\
\text { symptoms for both her conditions. }\end{array}$ \\
\hline
\end{tabular}

MS, multiple sclerosis.

progressive worsening of their symptoms was slow and subtle.

We compared the interviews of people that found about the SPMS diagnosis in different ways, for example, accidentally when visiting the hospital for other issues, or in one of the annual consultations or they suspected they had transitioned and asked the neurologist for confirmation. In contrast to the majority, the five participants who found out about the transition accidentally described being upset and shocked. These five people had MS between 3 years to 21 years (median $=12$ years).

[Neurologist's name] started other MRI's and tests and things and said that I'd progressed to secondary progressive. So, I was shocked and- I was shocked that I got signed off work, and it progressed. I thought he'd just say, 'You're signed off for a couple of weeks', not that and, I just thought, you know, 'If I sleep then I'll be all right'. (Female, 45 years, T1)

\section{Worsening of symptoms and emotional shifts}

Transitioning to SPMS also meant worsening of symptoms, and people described progressive worsening of symptoms including mobility, fatigue, vision, and bladder dysfunction, urinary tract infections and falls. There were further worsening of symptoms reported between the first and second interview. This deterioration also brought more changes in participants' lives.

Transitioning to SPMS also meant worsening of emotional issues. A few participants had a diagnosis of depression before or after the initial diagnosis of MS, which made managing MS more difficult. However, the majority of participants described dealing with other difficult emotions in both interviews, including feeling like a burden, being afraid of having accidents, being trapped or feeling embarrassed. They also expressed low self-esteem and confidence, and some participants described the uncertainty of whether they have the skills to cope with MS, accept the condition and deal with stress.

I had a bad fall last week where I split all my head open, so I am feeling a bit lack of confidence in just going out for a little walk up the road and back with my walker on my own. (Female, 54 years, T2)

Overall, in the second interview, participants talked in more depth about their psychological difficulties and challenges in coping over the years and presented a more severe picture than in the first round of interviews. Furthermore, people who described emotional 
Table 5 Examples of self-management and changes over time

\begin{tabular}{|c|c|c|c|}
\hline Interview & P01 & P05 & P21 \\
\hline $\begin{array}{l}\text { Pretransitioning } \\
\text { context }\end{array}$ & $\begin{array}{l}\text { She was diagnosed with SPMS } \\
\text { from the start. Before the MS } \\
\text { diagnosis, she had a higher } \\
\text { managerial role, which she left } \\
\text { after her diagnosis. }\end{array}$ & $\begin{array}{l}\text { He transitioned to SPMS } 6 \text { years } \\
\text { after initial diagnosis. Before the } \\
\text { MS diagnosis, his job taught him } \\
\text { how to anticipate risks and plan } \\
\text { accordingly. }\end{array}$ & $\begin{array}{l}\text { She transitioned to SPMS } 23 \text { years } \\
\text { after initial diagnosis. Before } \\
\text { the SPMS diagnosis, she was } \\
\text { diagnosed with depression and } \\
\text { other long-term conditions. }\end{array}$ \\
\hline First interview & $\begin{array}{l}\text { She reduced her activities, but } \\
\text { she was OK with that. She had } \\
\text { to change her goals to simpler } \\
\text { more achievable ones. She did } \\
\text { not need to see a psychologist } \\
\text { to help her adjust. She would } \\
\text { have liked to volunteer, but she } \\
\text { could not commit to it. }\end{array}$ & $\begin{array}{l}\text { He planned meticulously so he can } \\
\text { carry on his usual activities and } \\
\text { attended MS self-management } \\
\text { workshops. Keeping busy and } \\
\text { planning helped him to deal with } \\
\text { worries about the future. He was } \\
\text { involved with MS charities and MS } \\
\text { research to help others and also } \\
\text { learn more about MS. }\end{array}$ & $\begin{array}{l}\text { She tried to plan everything but } \\
\text { sometimes planning was too much } \\
\text { and it was not worth the trouble. } \\
\text { She wanted to exercise and see her } \\
\text { friends more, but she was too busy } \\
\text { with her healthcare appointments. } \\
\text { She believed that you have to do } \\
\text { things for yourself not wait for the } \\
\text { scientists to find the cure. }\end{array}$ \\
\hline
\end{tabular}

MS, multiple sclerosis; SPMS, secondary progressive multiple sclerosis.

challenges in the first interview described the same challenges in the second interview a year later.

\section{Arriving at the point of no help}

After transitioning to SPMS, most participants reported that they did not feel health services had anything more to offer since they could no longer have access to disease-modifying drugs. A few participants talked about the benefits of physiotherapy but either the sessions offered in the NHS were too few or physiotherapy was expensive to access privately. They saw their transition as a point beyond help.

I have an MS nurse but quite frankly you know I have come to an end what you can do, I don't feel I am getting any support at all at the moment. I feel I am being left to my own devices. Yes I see him every six months, every twelve months but there is nothing he can offer so you know it is a bit of a waste of time really. (Female, 54 years, T2)

However, a few participants reported doing their own research and identifying treatments that could potentially help them (eg, oxygen therapy and incontinence nurse) and then asked their healthcare team to refer them accordingly. Also, a few participants attended self-management courses run by local MS charities or access psychological treatments as part of research projects.
When asked whether there is any support that they would like to receive in the future, one participant said: 'I think there is quite a lot of support when you're first diagnosed but I think it tails off I think people find it more difficult to support you the longer you have the MS I think people become quite cynical about the help that can be got and cynical about what the NHS has to offer and cynical about the help that can be obtained as to whether it's any use or not' (Female, 65 years, T2). Most participants shared a similar opinion.

\section{Adaptive tasks and changes over time}

\section{Planning activities or scaling down activities}

Participants reported adjusting their holiday destinations and plans to take into account their limitations, without changing their previous lifestyle too much. Planning for future deterioration (eg, financially, house modifications) and planning activities and days out meticulously and well in advanced helped people feel in control. Sometimes, participants appeared to overestimate their limitations and underestimate their ability to cope in the future at the first interview compared with what people reported at the second interview. This discrepancy is illustrated below by the quotes of the same participant in the first and second interview.

I don't go too far now, I can only cope with about three and a half hours on the plane at the most. I 
can't go long distance or anything like that, you know long haul anymore, it's usually the Canary Islands or somewhere like that, somewhere nice and close. (Female, 54 years, T1)

I am still determined that I am going to travel and see as many places as I want. We went away for six weeks over January/February, we went to New Zealand and Australia. (Female, 55 years, T2)

However, at times, participants found it difficult to plan or modify their activities and instead scaled back, especially when the condition progressed rapidly, and almost all participants who had mentioned difficulties finding alternative activities in the first interview had the same difficulties in the second interview.

I can't read the same that I used to; I can't go on the computer; I can't really watch TV; gardening, the high impact exercises, you know, the long walk so everything's just had to be tailored down and you know brought into a shorter time period. The human is pretty good at finding ways around things... so yeah you just adapt um it's a struggle you know there's no two ways about it, but it is that life is definitely a struggle but again you get used to that really as well. (Female, 59 years, T2)

\section{Emotional regulation}

Strategies to manage emotional difficulties included distraction such as playing video games, reading books, going out for a meal or avoiding thinking and talking about the future, avoiding MS group meetings and spending the day sleeping. Some people tried to be positive by repeating 'things could have been worse'.

Furthermore, partners played an important role in emotionally supporting the participants by helping them adjust to new MS challenges or by being available to discuss participants' worries. People reported using the same strategies between the two interviews. A few participants talked about how they would have liked access to psychological services.

It would be nice to talk about how you feel about it, would be it'd be nice if...do you know it would be nice if just to have somebody there saying you're doing a grand job [Laugh] with how you're doing. Because you are isolated. (Female, 53 years T2)

However, two participants said that they were offered psychological support, but they thought this was unnecessary.

\section{Being social, fitting in and being of use}

For most of the participants, transitioning to SPMS also meant increased mobility problems and use of a wheelchair. Use of a wheelchair also posed accessibility issues leading to more carefully planned outings. Even though going out came with more difficulties, and at times people felt it was easier to stay in, most talked about the importance of being with friends and family and retaining relationships and also meeting new people. Participants described getting involved in charity work, MS research and helping others. They reported that this gave them a new purpose, they learnt new things and met people. Participants who talked about the importance of being social or helping others in the first interview also talked about it in their second interview, as illustrated below by the same participant at the two time points.

... [G] oing out with friends, going out for dinner, going and mixing with other people, which I would have quite enjoyed before and not thought anything about it, but now I think, 'oh do I really want to go?' but then I force myself, you have got to go, because then when I do go, I do enjoy it and I do feel better because your mood's lifted and once you are moving around, things are easier. (Female, 59 years, T1)

We've got the local MS branch, we meet twice a month, first and third Tuesdays of the month. I find that very helpful. I do find that helpful to talk to other people that have got the same sorts of problems that you've got, gone through the same things. And again, there's somebody there that, it's not perhaps a close friend, but has become or is becoming more of a close friend that we will see one another outside of the MS branch. (Female, 59 years, T2)

\section{DISCUSSION}

Reflecting on the SPMS diagnosis, people overall did not express trauma or distress, only on the occasions, the diagnosis came as a surprise. People who have recently transitioned to SPMS reported facing a worsening of the condition alongside increased emotional challenges. In the second interview, most people described the increased severity of their symptoms and more emotional difficulties. Participants reported detailed planning, distractions and remaining as active and as involved in the community as possible helped to cope with the condition. Some participants overestimated their limitations and underestimated their capacity to cope between the first and the second interview but overall most reported using similar coping strategies between the two time points. A common theme across all interviews was a sense of abandonment from the healthcare services and the sense that nothing can be done at this stage of their condition. Therefore, providing appropriate support after the transition diagnosis is vital.

A qualitative study of people recently diagnosed with MS showed that psychological well-being was described as precariously contingent on reasonable current and future health status, ${ }^{31}$ for example, people were not sure whether they would be able to cope if they lost their job or had to use a wheelchair. The current study examines what happens after people have moved to SPMS. 
Participants in our study talked about increased disability since they have transitioned to SPMS or between the first and second interview, but despite these increased difficulties, people felt that healthcare professionals had nothing more to offer and there was nothing more they could do to control their emotional or physical symptoms. Focusing on well-being is often on diagnosable depression and anxiety. However, participants in the present study described having to deal with challenging emotions that may not reflect in these clinical diagnoses.

An essential finding of this study is that people who described some challenges with self-management in the first interview described the same challenges in the second interview a year later. This can be linked to their perception of SPMS as the stage where nothing further can be done to manage things. According to the Common Sense Model, ${ }^{32}$ being diagnosed with an illness that is perceived as more controllable will lead to less distress and more control efforts such as seeking advice on symptom management. As people move from RRMS to SPMS, the capacity of personal and treatment control declines and creates a significant challenge in adapting to the change by identifying areas that they can still have control while letting go of unattainable goals. ${ }^{33}$

Participants in the current study reported that there is nothing they or healthcare professionals can do to manage their increasing limitations. Even though self-management interventions in progressive MS are scarce, there is some preliminary evidence of interventions that could help with symptom management. For example, endurance training can improve walking, ${ }^{34}$ progressive resistance training may improve lower limb strength, ${ }^{35}$ bodyweight-supported treadmill can reduce pain ${ }^{36}$ and mindfulness training can reduce anxiety, depression and impact of MS. ${ }^{37}$ Where available, healthcare professionals should signpost patients to appropriate services that can help with MS symptoms but more needs to be done to find ways of developing these services, so they are more readily available.

The present study has certain significant strengths. First, to our knowledge, it is the first study attempting to investigate challenges and adaptive tasks shortly after people have transitioned to SPMS. The particular advantage of the present study is its longitudinal approach that allowed the identification of patterns over time. This showed that whereas more severe emotional and physical symptoms were reported in the second interview, these did not result in different or more challenges. While this may suggest participants feeling more comfortable in opening up at time two, having built a rapport with the interviewer, it may also reflect the lack of support people were receiving. Finally, a strength of this study also lies in the specificity of the sample selected who were all people who had transitioned to SPMS within the previous 5 years.

The study has certain limitations. First, the qualitative exploratory nature of the study does not allow for causal relationships to be established. Second, getting an SPMS diagnosis may take years.$^{6}$ Therefore, it is hard to determine whether the challenges described are linked to having received an official diagnosis or to the challenges faced by increased disability, as we did not interview people just before being diagnosed and straight after. Furthermore, participants self-reported transitioning to SPMS, although they were asked to confirm that they have received the transitioning diagnosis officially from an MS health professional, we did not verify this information by cross-checking their medical records. Also, their recollections of the time of the diagnosis might not be accurately represented during the interviews that took place up to 5 years later. Finally, telephone interviews might be considered inferior to face to face, since rapport can be harder to establish. However, research indicates both telephone and in-person interviews can be used productively in qualitative research, ${ }^{38}$ with the former potentially allowing participants to feel more relaxed and willing to disclose sensitive information, ${ }^{39}$ enhancing the data's trustworthiness.

Regardless of the above limitations, the findings presenting here underline the additional physical and emotional challenges people face when transitioned to SPMS and that people try to adapt by planning, finding distractions and remaining social, but they reported there was nothing further to do regarding symptom management. Identifying physical and emotional challenges at the time of the diagnosis to SPMS will help referral to appropriate services within a multidisciplinary clinical team. Offering people options for continuing symptoms management at the time of SPMS diagnosis may help with feelings of helplessness that accompany the diagnosis.

Acknowledgements The authors would like to thank the people with MS who took part in this study.

Contributors $A B$ and $R M-M$ designed the study. $A B$ conducted the interviews, led the data analysis and drafted the manuscript. MM contributed to the development of the topic guide, oversaw data collection and analysis and contributed to drafts of the paper. RM-M advised on the conduct of the research, contributed towards refining themes, interpretations of the findings, and drafts of the paper.

Funding Multiple Sclerosis UK supported this work under grant reference 4. Competing interests None declared.

Patient consent for publication Obtained.

Ethics approval The current study was approved by the West of Scotland Research Ethics Committee (14/WS/0077).

Provenance and peer review Not commissioned; externally peer reviewed.

Data sharing statement Paper trail and NVivo coding files are available from the corresponding author.

Open access This is an open access article distributed in accordance with the Creative Commons Attribution Non Commercial (CC BY-NC 4.0) license, which permits others to distribute, remix, adapt, build upon this work non-commercially, and license their derivative works on different terms, provided the original work is properly cited, appropriate credit is given, any changes made indicated, and the use is non-commercial. See: http://creativecommons.org/licenses/by-nc/4.0/.

\section{REFERENCES}

1. Mackenzie IS, Morant SV, Bloomfield GA, et al. Incidence and prevalence of multiple sclerosis in the UK 1990-2010: a descriptive study in the General Practice Research Database. J Neurol Neurosurg Psychiatry 2014;85. 
2. Compston A, Coles A. Multiple sclerosis. Lancet 2008;372:1502-17.

3. Fisniku LK, Brex PA, Altmann DR, et al. Disability and T2 MRI lesions: a 20-year follow-up of patients with relapse onset of multiple sclerosis. Brain 2008;131:808-17.

4. Lublin FD, Reingold SC. Defining the clinical course of multiple sclerosis: results of an international survey. National Multiple Sclerosis Society (USA) Advisory Committee on Clinical Trials of New Agents in Multiple Sclerosis. Neurology 1996;46:907-11.

5. Tremlett H. Secondary Progressive Multiple Sclerosis. MS in Focus 2009;13:13-14.

6. Katz Sand I, Krieger S, Farrell C, et al. Diagnostic uncertainty during the transition to secondary progressive multiple sclerosis. Mult Scler 2014;20:1654-7.

7. Gross $\mathrm{HJ}$, Watson C. Characteristics, burden of illness, and physical functioning of patients with relapsing-remitting and secondary progressive multiple sclerosis: a cross-sectional US survey. Neuropsychiatr Dis Treat 2017;13:1349-57.

8. Planche V, Gibelin M, Cregut D, Pereira B, et al. Cognitive impairment in a population-based study of patients with multiple sclerosis: differences between late relapsing-remitting, secondary progressive and primary progressive multiple sclerosis. Eur $\mathrm{J}$ Neurol 2016;23:282-9.

9. Papathanasiou A, Messinis L, Georgiou VL, et al. Cognitive impairment in relapsing remitting and secondary progressive multiple sclerosis patients: efficacy of a computerized cognitive screening battery. ISRN Neurol 2014;2014:1-7.

10. Denney DR, Sworowski LA, Lynch SG. Cognitive impairment in three subtypes of multiple sclerosis. Arch Clin Neuropsychol 2005;20:967-81.

11. Bakshi R, Shaikh ZA, Miletich RS, et al. Fatigue in multiple sclerosis and its relationship to depression and neurologic disability. Mult Scler 2000;6:181-5.

12. Thorne S, Con A, McGuinness L, et al. Health care communication issues in multiple sclerosis: an interpretive description. Qual Health Res 2004;14:5-22.

13. Vleugels $L$, Pfennings $L$, Pouwer $F$, et al. Psychological functioning in primary progressive versus secondary progressive multiple sclerosis. Br J Med Psychol 1998;71(Pt 1):99-106.

14. Montel SR, Bungener C. Coping and quality of life in one hundred and thirty five subjects with multiple sclerosis. Mult Scler 2007;13:393-401.

15. McNulty K, Livneh H, Wilson LM. Perceived Uncertainty, Spiritual Well-Being, and Psychosocial Adaptation in Individuals With Multiple Sclerosis. US: Educational Publishing Foundation, 2004:91-9.

16. Mohr DC, Dick LP, Russo D, et al. The psychosocial impact of multiple sclerosis: exploring the patient's perspective. Health Psychol 1999;18:376-82.

17. Olsson M, Lexell J, Söderberg S. The meaning of women's experiences of living with multiple sclerosis. Health Care Women Int 2008;29:416-30.

18. Olsson M, Skär L, Söderberg S. Meanings of feeling well for women with multiple sclerosis. Qual Health Res 2010;20:1254-61.

19. Davies F, Edwards A, Brain K, et al. 'You are just left to get on with it': qualitative study of patient and carer experiences of the transition to secondary progressive multiple sclerosis. BMJ Open 2015;5:e007674.

20. O'Loughlin E, Hourihan S, Chataway J, et al. The experience of transitioning from relapsing remitting to secondary progressive multiple sclerosis: views of patients and health professionals. Disabil Rehabil 2017:39:1821-8.

21. Fiest KM, Walker JR, Bernstein CN, et al. Systematic review and meta-analysis of interventions for depression and anxiety in persons with multiple sclerosis. Mult Scler Relat Disord 2016;5:12-26.

22. Jongen PJ, Heerings M, Ruimschotel R, et al. An intensive social cognitive program (can do treatment) in people with relapsing remitting multiple sclerosis and low disability: a randomized controlled trial protocol. BMC Neurol 2016;16:81.

23. Patton M. Qualitative evaluation and research methods. Thousand Oaks, California: Sage Publications Ltd, 1990.

24. Guest G, Bunce A, Johnson L. How many interviews are enough?: an experiment with data saturation and variability. Field Methods 2006;18:59-82.

25. Scalfari A, Neuhaus A, Degenhardt A, et al. The natural history of multiple sclerosis: a geographically based study 10 : relapses and long-term disability. Brain 2010;133:1914-29.

26. Eriksson M, Andersen O, Runmarker B. Long-term follow up of patients with clinically isolated syndromes, relapsing-remitting and secondary progressive multiple sclerosis. Mult Scler 2003;9:260-74.

27. Tremlett H, Yousefi M, Devonshire V, et al. Impact of multiple sclerosis relapses on progression diminishes with time. Neurology 2009;73:1616-23.

28. Braun V, Clarke V. Using thematic analysis in psychology. Qual Res Psychol 2006;3:77-101.

29. Payne S. Interview in qualitative research. In: Memon A, Bull R, eds. Handbook of psychology of interviewing. London: Wiley and Sons, 1999:89-102.

30. Glaser B, Strauss SA. Discovery of grounded theory. Strategies for qualitative research. New York: Aldine de Gruyter, 1967.

31. Dennison L, Yardley L, Devereux A, et al. Experiences of adjusting to early stage Multiple Sclerosis. J Health Psychol 2011;16:478-88.

32. Leventhal H, Diefenbach M, Leventhal EA. Illness cognition: using common sense to understand treatment adherence and affect cognition interactions. Cognit Ther Res 1992;16:143-63.

33. Heckhausen J, Wrosch C, Schulz R. A motivational theory of lifespan development. Psychol Rev 2010;117:32-60.

34. Briken S, Gold SM, Patra S, et al. Effects of exercise on fitness and cognition in progressive MS: a randomized, controlled pilot trial. Mult Scler 2014;20:382-90.

35. Latimer-Cheung AE, Pilutti LA, Hicks AL, et al. Effects of exercise training on fitness, mobility, fatigue, and health-related quality of life among adults with multiple sclerosis: a systematic review to inform guideline development. Arch Phys Med Rehabil 2013;94:1800-28.

36. Wier LM, Hatcher MS, Triche EW, et al. Effect of robot-assisted versus conventional body-weight-supported treadmill training on quality of life for people with multiple sclerosis. J Rehabil Res Dev 2011;48:483-92.

37. Bogosian A, Chadwick P, Windgassen S, et al. Distress improves after mindfulness training for progressive MS: A pilot randomised trial. Mult Scler 2015;21:1184-94.

38. Sturges JE, Hanrahan KJ. Comparing telephone and face-to-face qualitative interviewing: a research note. Qualitative Research 2004:4:107-18.

39. Novick $\mathrm{G}$. Is there a bias against telephone interviews in qualitative research? Res Nurs Health 2008;31:391-8. 